\title{
PENERAPAN KONSEP PERENCANAAN SISTEM INFORMASI \\ AKADEMIK PERGURUAN TINGGI
}

\begin{abstract}
Abdul Faqih
UT UPBJJ Surabaya

Abstraksi

Pada masa sekarang tahun 2000 an kemudian berkembang menjadi pentium M, Pentium Core dan pentium Core 2, dan sejak tahun 2005 kecepatanya super canggih menjadi 1,6-2,95 GHz. Terkait dengan perkembangan ICT yang akan lebih cepat, dan meluas dimasa-masa akan datang, mari kita gunakan segala daya upaya dan akal pikiran kita semua untuk mempelajari, memanfaatkan dan mengembangkan ICT tersebut secara kreatif, inovatif dan produktif agar karya-karya kita bisa menjadi kenyataan dapat mendorong perkembangan ilmu pengetahuan dan teknologi, kususnya di era manajemen sistem informasi dimana kita dapat melakukan pengolahan data dalam waktu yang singkat, cepat dan akurat.
\end{abstract}

Keywords: ICT, Sistem Informasi, akademik

\section{PENDAHULUAN}

Perkembangan taknologi ICT (Information and Communication Technology) pada satu dasawarsa terakhir ini demikian pesat, kususnya perkembangan teknologi informasi komputer berbasis digital semakin meningkat dan meluas, hampir semua teknologinya tidak terjangkau kecepatannya oleh kita. Dengan perkembangan yang demikian pesat, cepat, meluas, dan tiada henti, apakah kita hanya ingin menjadi penonton, atau kita hanya ingin menjadi 'pembajak' tentu seharusnya tidak. Sebagai contoh pada masa yang lalu kita bisa memperhatikan di era perkembangan perangkat keras (hardware) jenis prosesor Intel pada tahun 1970 an kecepatannya baru $740 \mathrm{kHz}$, dan tahun 1980 kecepatannya menjadi antara $16-40 \mathrm{MHz}$, tahun 1993 meningkat menjadi antara 100-233 MHz ( Pentium I ), tahun 1977 antara 233-450 MHz ( Pentium II ) dan selanjutnya menjadi pentium III tahun 1999 kecepatannya mencapai 1,4 GHz, Pentium IV tahun 2000 kecepatanya 1,3-3,8 GHz (Bambang. W, 2008).

Pada masa sekarang tahun 2000 an kemudian berkembang menjadi pentium M, Pentium Core dan pentium Core 2, dan sejak tahun 2005 kecepatanya super canggih menjadi 1,6-2,95 GHz. Terkait dengan perkembangan ICT yang akan lebih cepat, dan meluas dimasa-masa akan datang, mari kita gunakan segala daya upaya dan akal pikiran kita semua untuk mempelajari, memanfaatkan dan mengembangkan ICT tersebut secara kreatif, inovatif dan produktif agar karya-karya kita bisa menjadi kenyataan dapat mendorong perkembangan ilmu pengetahuan dan teknologi, kususnya di era manajemen sistem informasi dimana kita dapat melakukan pengolahan data dalam waktu yang singkat, cepat dan akurat. 
Perkembangan ICT tersebut juga telah didukung oleh perkembangan perangkat lunak (software) yang semakin canggih, tepat guna dan multi fungsi. Software-software tersebut berfungsi untuk menyelesaikan atau memecahkan masalah-masalah pengolahan data yang kita jumpai sehari-hari dalam aktivitas manajemen atau rancangan sistem informasi. Didalam mengelola sumber daya informasi sekarang telah banyak diperjual belikan berbagai jenis software, baik software aplikasi maupun software pemrograman, software ini penting karena adanya kebutuhan untuk mengolah data maupun menganalisis data dan kebutuhan akan adanya produk-produk software aplikasi, seperti pemrograman, aplikasi sistim basis data, dan perangkat lunak lainnya telah menjadi kebutuhan prioritas dalam kehidupan sehari-hari.

Pada masa sekarang ini, software tidak hanya membantu manusia dalam melakukan pekerjaan rutinnya, akan tetapi menjadi kunci sukses dalam persaingan bisnis dan persaingan sumber daya informasi. Pada dewasa ini pemanfaatan Teknologi Informasi (TI), maupun Sistem Informasi (SI) berfungsi mendukung suksesnya setiap perusahaan, bisnis, pengembangan organisasi maupun institusi pendidikan. Menurut Miles \& Snow (2001), organisasi berkembang dari tipe fungsional ke tipe divisional, selanjutnya berkembang ke tipe matrix, dan akhirnya berkembang ke bentuk dynamic networking. Didalam bentuk dynamic networking Organization peranan teknologi informasi dan Sistem informasi sangatlah penting untuk meraih sukses dan persaingan di masa depan.

Begitu pentingnya peranan TI \& SI dalam membentuk dynamic networking Organization, sehingga memicu munculnya inovasi-inovasi baru dalam berbagai aplikasi yang dioperasikan, diawali dengan berkembangnya Internet dan E-mail, kemudian diikuti dengan munculnya teknologi informasi baru di bidang bisnis dan perbankan seperti penerapan E-Commerce, E-Business, EBanking dan lain-lain. Begitu juga dalam dunia pendidikan tidak ketinggalan yaitu penerapan EEducation, E-Learning, E-Teaching dll. Aplikasi ini dalam dunia pendidikan semakin meluas dalam rangka menunjang perbaikan mutu. Salah satu aplikasi sistem informasi pendidikan yang telah direrapkan di dunia pendidikan tinggi adalah Sistem Informasi Akademik (SIA), dan mencakup bidang aktivitas seperti sistem perkuliaham, sistem seleksi mahasiswa baru, sistem perpustakaan, sistem administrasi pembelajaran dan aktivitas lainnya.

Kuliah di perguruan tinggi akan lebih interaktif, inovatif, efektif, dan menarik apabila ada animasi untuk menerangkan ilmu yang sedang dipelajari dalam perkuliahan maupun diluar kuliah. Guna menunjang pencapaian tujuan-tujuan pendidikan masih banyak peluang untuk membuat softwaresoftware aplikasi, untuk mendukung pembelajaran yang lebih baik dan bermutu, menyenangkan dan interaktif. Sehingga secara substansial instansi pendidikan yang terkait dituntut menyediakan sarana prasarana pendidikan yang terkait dengan E-Education, E-Learning, E-Teaching, dan SIA disamping harus mampu mampu menyediakan SDM pendukung yang berkualitas dan trampil sebagai brainware. Semua sistem informasi tersebut diterapkan karena adanya tuntutan untuk 
meningkatkan kualitas pendidikan yang mereka kelola, dengan harapan menghasilkan ouput sebagai SDM yang bermutu berstandar Nasional maupun berstandar Internasional.

\section{MELAKUKAN IDENTIFIKASI SISTEM INFORMASI AKADEMIK}

Persaingan yang semakin ketat diantara perguruan tinggi akan mendorong pengelola pendidikan tinggi untuk dapat memberikan pelayanan yang maksimal dan lebih baik serta mudah. Disamping itu dengan adanya era TI dan SI, maka aplikasi sistem informasi dalam penyelenggaraaan pendidikan tinggi sudah tidak bisa ditawar-tawar lagi dengan tujuan penyediaan informasi bagi para stakeholder. Pengelolaan informasi dengan TI Sistem informasi telah menjadi kebutuhan penting dan memdesak demi suksesnya visi dan misi perguruan tinggi yang bersangkutan, karena TI sistem informasi akan mempermudah dan mempercepat dalam pelayanan akademik, manajemen perkuliahan serta administrasi pendidikanya. TI Sistem informasi, dapat mengotomatisasi segala prosedur dan proses dari pemasukan informasi, menyimpan, menginformasikan dan pembaharuan informasi serta selalu dijamin up to date

Berkaitan dengan penyediaan sistem informasi bagi para stakeholder pendidikan tinggi, maka didalam merancang sistem informasi pendidikan tinggi perlu ditempuh langkah-langkah identifikasi masalah dalam rangka pendekatan kepada sistem akademik dengan konsep sebagai berikut :

1. Melakukan identifikasi dan analisis kebutuhan sistem informasi akademik secara koheren, detail dan menyeluruh yang terkait dengan strategi pendidikan tinggi.

2. Melakukan identifikasi dan analisis untuk pengembangan sistem informasi akademik guna memperkaya metode-metode yang akan diterapkan.

3. Membuat proyek-proyek perencanaan sistem informasi dari sebuah permasalahan, diubah menjadi software sistem informasi yang akan disajikan untuk stakeholder

4. Merancang sistem informasi dari komponen-komponen yang saling terkait antara satu dan lainnya. Seperti kaitan antara manajemen, organisasi, proses, prosedur, SDM, kebijakan dan lainnya.

5. Merancang database model konseptual, untuk menunjukkan entity dan relasinya berdasarkan proses yang diinginkan.

6. Mengimplementasikan dan mendokumentasi sistem informasi akademik secara efektif dan efisien didalam sebuah manajemen dan organisasi sehingga dapat mencapai visi misi perguruan tinggi yang diinginkan.

Sebagai langkah berikutnya adalah menerapkan perancangan sistem informasi akademik, yaitu pengambilan keputusan dan usaha-usaha pendekatan sistem yang direncanakan, disini dapat menentukan apa-apa yang dikehendaki atau ingin perancang. Pada masa sekarang secara garis besar Sistem Informasi akademik Perguruan Tinggi terbagi menjadi sepuluh komponen perencanaan utama yaitu :

1. Menerapkan Sistem Informasi Penerimaan mahasiswa baru.

2. Menerapkan Sistem Informasi Akademik Kepegawaian. 
3. Menerapkan Sistem Informasi Akademik Perkuliahan.

4. Menerapkan Sistem Informasi Akademik Keuangan.

5. Menerapkan Sistem Informasi Akademik Kurikulum.

6. Menerapkan Sistem Informasi Kemahasiswaan.

7. Menerapkan Sistem Informasi Perpustakan.

8. Menerapkan Sistem Informasi Sumber Daya Manusia.

9. Menerapkan Sistem Informasi Sumber Daya Sarana Prasarana.

10. Menerapkan Sistem Informasi Manajemen Pembelajaran.

\section{TAHAP PERANCANGAN DATA SISTEM INFORMASI}

Kata data dalam bahasa inggris berasal dari kata datum, dari bahasa latin yang berarti fakta. Data bagi komputer adalah segala sesuatu yang dapat dilambangkan, dikodekan atau didigitalisasikan ke dalam lambang-lambang atau kode-kode yang dimengerti oleh komputer (Bambang.W, 2008). Dalam perancangan data di komputer secara kasar dapat dikatakan bahwa data dapat berupa input angkaangka, huruf-huruf, gambar atau simbul-simbul, atau apapun yang dapat dimasukkan (diinput) ke komputer dan di keluarkan (dioutput) dari komputer. Berikut ini dipaparkan langkah-langkah bagaimana perancangan data bagi komputer :

1. Pengkodean Byte : Satu byte dapat dikatakan sebagai sebuah karakter dan merupakan sekumpulan dari bit. Sedangkan bit merupakan unit terkecil dari informasi bagi kompoter. Permasalahannya berapa banyak bit penggabungan itu harus dilakukan. Pada umumnya sebuah Byte terdiri atas 8 bit yang disebut dengan octet yang dapat merepresentasikan 256 nilai.

2. Pembuatan Field: Ada beberapa istilah lain untuk field selain disebut atribut, ada juga yang menyebut Column (Kolom), data member dan variable. Di computer data yamg neniliki beberap bagian dapat dibagi menjadi beberapa atribut. Sebagai contoh perancangan field misalnya data mahasiswa dapat dibagi menjadi beberapa atribut yang berbeda yaitu nama, alamat, jenis kelamin, tempat tanggal lahir, status, penghasilan orang Tua, prestasi akademis dan sebagainya. Jadi atribut merupakan ciri atau karakteristik dari suatu data dan atribut juga merupakan kumpulan dari byte (karakter).

3. Pembuatan Record : Apabika kita memandang suatu lingkungan, misalkan dikampus kita melihat beberapa obyek seperti orang kampus, administrasi, manajemen, proses akademik dan sebagainya.. Maka satu obyek itu kita identifikasi lagi misalnya orang dalam kampus itu ternyata statusnya sebagai dose, mahasiswa, karyawam, pimpinan, keamanan, kebersihan atau sopir. Jika kita pandang seorang mahasiswa, ia memiliki identitas seperti : nama, alamat, jenis kelamin, tempat tanggal lahir, status, penghasilan orang Tua, prestasi akademis dan sebagainya. Tentu tidak semua atribut tersebut diinput kedalam komputer, akan tetapi cukuplah yang sangat diperlukan saja. Satu rangkaian data identitas mahasaswa diatas kemudian beberapa atribut dipilih ini dinamakan record. 
4. Pembuatan File, Entity Set, Object, dan Berkas : Kumpulan dari record-record tersebut akan membentuk sebuah data file. Dalam satuan file inilah data-data bisa disimpan dikomputer. Jadi apabila sebuah file kita gambarkan sebagai sebuah table maka record adalah sebuah baris (row) dan file adalah kolom. Selain data file ada ribuan jenis file di hard disk computer yang sedang dioperasikan. Umumnya nama file terdiri dari dua bagian yaitu nama file (file name) dan nama panjang dari file (extension file name), nama panjang inilah merupakan petunjuk dari jenis file apa yang dibuat.

5. Pembuatan Database atau Basis Data : Database yang dirancang adalah database dalam pengertian ukuran darai data (yang dimulaia darai ukuran data terkecil dikomputer, yaitu bit). Sekumpulan dari data file di dalam suatu enterprise disebut dengan database. Maka database di lingkungan perguruan tinggi adalah data file dari data-data mahasiswa, dosen, staff, pimpinana, KRS, KHS, pembayaran, gaji, sarana, prasarana dan sebagainya. Isi didalam database ini adalah segala sesuatu catatan (data file) yang diperlukan dari suatu lingkungan perguruan tinggi (enterprise) dan disatukan disatukan dalam satu tempat penyimpanan dalam komputer yang disebut dengan database. Jika setiap database kemudian disatukan lagi, kumpulan dari database yang ada ditiap-tiap unit kerja selanjutnya disebut bank data. Tentu saja untuk penyatuan tersebut diperlukan syarat-syarat yang sesuai dengan software dan hardware yang di operasikan.

6. Menggunakan Database Management System (DBMS) : Pemakaian DBMS adalah untuk mengelola database yang di operasikan. Misalnya DBMS yang ada dipasaran adalah MySQL, Orecle, Microsoft SQL, Server, Informix, Progress 4GL dan sebagainya. DBMS mengandung pengertian, sekumpulan program-program software yang sangat kompleks untuk mengontrol organisasi data dan alat penyimpan data di dalam database yang telah dibuat secara paket dan membantu kita dalam memodifikasi data-data yang telah ada dalam database tersebut. Ada tiga modifikasi database model yaitu : (1) Model Hierarki (hierarchical model), (2) Model Jaringan (network model), (3) Model Relasional (relational model). Model-model itu berkembang karena ada beberapa kebutuhan pemakai yang semakin bervariasi.

7. Database Administrator (DBA) : Setiap pengoperasian database pasti memerlukan seorang administrator untuk mengelolanya. Namun untuk database yang besar dan komplek tentu dibutuhkan grup pengelola DBA yang saling bekerjasama dalam menangani sistem database yang dikomunikasikan. Pada umumnya tugas tim DBA adalah sebagai berikut: (1) perencanaan (planning), (2) pengorganisasian (organnising), (3) pengembangan (development), (4) pemeliharaan (maintenance), (5) mengontrol dan memonitor. Jadi DBA adalah grup Brainware yang tugasnya mengelola dan bertanggungjawab atas segala aspek yang berkaitan dengan database.

\section{TAHAP PERANCANGAN SISTIM KOMPUTER}

Ilmu komputer adalah ilmu yang mempelajari dasar-dasar teori dari informasi dan komputasi serta implementasi dan aplikasi dari sistem komputer itu sendiri (Bambang W: 2008). Sedangkan bagian- 
bagian dari sistem komputer mengarah kepada perangkat keras (hardware) yang merupakan bagian dari computer engineering, perangkat lunaka (software) yang merupakan bagian dari software engineerring . Komputer merupakan suatu sistem teknologi informasi yang dapat menerima dan mengolah data-data menjadi informasi yang akurat, tepat dan cepat dalam pemrogramannya. Oleh karena itu agar komputer dapat bekerja dengan baik maka harus melibatkan tiga hal utama yaitu : (1) Hardware, (2) Software dan (3) Brainware.

Hardware Input Unit: Komponen ini merupakan bagian dari perangkat keras yang berfungsi sebagai alat untuk input atau memasukkan data-data yang akan diproses. Perangkat input yang harus dipersiapkan antara lain : Keyboard, Mouse, Camera, Scanner, CCTV, Monitor, CD-Rom Drive, DVD-Rom Drive, Digital Card Reader, 3D Laser Scanner dan lain sebagainya.

Hardware Processing Unit : perangkat keras processing unit ini sering disebut CPU (Central Processing Unit) yang berpungsi sebagai jantungnya komputer, CPU dapat melakukan pekerjaan utama seperti proses-proses perhitungan, pengaturan hubungan logika dan kontrol data serta mengalokasikan tempattempat penyimpanan sementara atau permanen berbentuk file-file dalam CPU. Dalam pemilihan prosesor yang akan dioperasikan pada pembuatan sistem infirmasi antara lain prosesor jenis : Intel Intanium, Intelo Intanium 2, Pentium M, Pentium extreme Ed, Pentium Core, Pentiun Core 2 dan lain sebagainya.

Hardware Output Unit : perangkat ini merupakan peralatan yang berfungsi untuk menyajikan output untuk menghasilkan tampilan sistem informasi yang dikehendaki. Bentuk dari peralatan output antara lain : Monitor, Printer, Projector, Plotter, Speaker dan lain sebagainya.

Software berfungsi sebagai pengataur aktivitas kerja komputer dan semua intruksi yang mengarah pada kinerja sistem komputer. Perangkat lunak ini untuk menjembatani interakasi user dengan sistem komputer yang tugasnya hanya memahami bahasa mesinkomputer. Secara umum perangkat lunak yang harus dipersiapkan yaitu: Operating system software dan Application software.

Pilihan Operating system software antara lain : Windows, Linux, Unix, MS-DOS, Novell, Free BSD, Macintosh dan lain sebagainya. Dan pilihan Application software antara lain : (1) Business \& Office Application (Contoh: Microsoft Office, Star Office, Open office, MS-Office, Koffice, Abword dan lainnya). Kita juga bisa membuat sendiri software aplikasi ( contoh : membuat software Aplikasi bisnis, aplikasi sistem informasi akademik, aplikasi periklanan aplikasi manajemen rumah sakit dan lain sebagainya). DataBase Application (Contoh : MS SQL, MySQL, FoxBase, Orecle, SQL Server dan lainnya). Graphic Design Application (Contoh : AutoCad, Pro Design, Corel Draw, Adobe Ilustrator dab lainnya).

\section{PROYEK SISTEM INFORMASI YANG DIRENCANAKAN}

\subsection{Perencanaan E-Registration}


Sistem Informasi Akademis (E-Registration) dalam rancangan ini meliputi pendaftaran mahasiswa, pendaftaran mata kuliah, dan aktifitas perkuliahan serta informasi akademis tentang KRS dan KHS rancangan system ini disebut dan dikemas dalam sistem informasi E-Registration. Proses regristasi setiap awal semester baik mahasiswa baru maupun lama dan proses pengambilan mata kuliah adalah suatu hal yang paling pertama harus dilakukan dalam proses akademis sebelum adanya proses belajar-mengajar.

Kemudahan dan kecepatan pendaftaran dan registrasi adalah hal yang utlak diperlukan dan dibutuhkan oleh mahasiswa baru atau lama. Hal ini menuntut perguruan tinggi menyiapkan sebuah E-Registration yang terpadu seperti dijelaskan pada sub bab diatas. Kendala waktu dan jarak terkadang menyebabkan proses registrasi menjadi lambat dan tidak efisien. Manajemen sistem informasi yang belum terintegrasi membuat pencarian histori data menjadi tidak maksimal sehingga terkadang mengalami kesulitan .

Dengan perkembangan sistem informasi berbasis komputer yang semakin meningkat dan menyajikan kemudahan bagi penggunanya, sangat perlulah sebuah perguruan tinggi untuk ikut serta dalam pengunaan dan penerapan teknologi informasi tersebut sebagai penunjang kegiatan akademis. Walaupun masih banyak permasalahan manajemen sistem informasi, terutama masalah E-Registration baik untuk pendaftaran mahasiswa baru maupun lama serta pengambilan mata kuliah sesungguhnya masih belum memasarakat. Tetapi teknologi informasi bisa mengatasi segala permasalahan manajemen sistem informasi berbasis komputer yang mana pada saat ini merupakan kebutuhan penting untuk meningkatkan kualitas informasi. Apalagi teknologi informasi berbasis web telah bisa menyajikan segala sesuatu yang dibutuhkan oleh banyak pihak dan bisa menginformasikan segala bidang kegiatan sebuah perguruan tinggi.

Teknologi informasi berbasis web kususnya E-Registration untuk kegiatan akademis bisa menjembatani jarak dan waktu serta integrasi informasi yang saat ini banyak menjadi andalan baik pada penyelenggara pendidikan tinggi maupun mahasiswa yang sedang menempuh perkuliahan serta alumninya. Kemudahan dalam hal merancang dan menerapkan E-Registration ini mutlak diperlukan agar penyelenggara pendidikan tinggi dalam kinerjanya dapat memudahkan bagi pihak manajemen pendidikan sehingga meringankan dalam memonitoring perkembangan kegiatan.

E-Registration secara on-line membuat proses pendaftaran bisa dilakukan dimana saja tanpa harus ada antrian yang membosankan, baik terhadap mahasiswa maupun petugas pendaftaran. Mahasiswa bisa melakukan pendaftaran mata kuliah atau berkonsultasi dengan dosen pembimbing tanpa harus bertatap muka. Meskipun E-Registration atau Pendaftaran secara on-line membuat proses pendaftaran bisa dilakukan dimana saja tanpa harus ada antrian yang membosankan, baik terhadap mahasiswa maupun petugas pendaftaran. Mahasiswa bisa melakukan pendaftaran mata kuliah atau berkonsultasi dengan dosen pembimbing tanpa harus bertatap muka. 
- Efisiensi, dimana kecepatan dan kemudahan serta efisien waktu dalam pendaftaran dan regristrasi menjadi kebutuhan mahasiswa.

- Efisien \& Akursi, dimana validasi informasi pendaftaran dan hasil penilaian akademis yang benar, valit dan tepat serta trasparan dapat dilakukan.

o Bagi Perguruan Tinggi :

- Kontribusi kepada nilai-tambah perguruan tinggi yang telah menerapkan teknologi informasi : "the right information to the right people at the right time".

- Dapat menyajikan Informasi yang andal, akurat, lengkap, terstruktur \& terorganisir.

- Optimasi infrastruktur yang tersedia di perguruan tinggi dapat dilakukan secara efektif dab efisien.

- Integrasi, kelengkapan dan keterkaitan data yang terstruktur dan baik dapat ditingkatkan.

» Tujuan dari penggunaan E-Regsitration :

- Dapat membuat sebuah sistem informasi yang terintegrasi dengan baik.

- Dapat meningkatkan efektifitas dan efisiensi dalam proses pendaftaran.

- Dapat meningkatkan potensi sumber daya manusia.

- dapat memudahkannya pemantauan proses kegiatan akademik.

\section{» Manfaat dari penggunaan E-Regsitration :}

- Memudahkan mahasiswa melakukan pendaftaran dengan adanya informasi mata kuliah yang akan diambil dan yang telah diambil secara lengkap dan akurat dan bisa dilakukan di jaringan lokal intranet maupun internet.

- Memudahkannya administrator dalam hal manajemen database pendaftaran mahasiswa dan histori nilai akademis.

- Memudahkannya dosen dalam memantau perkembangan penilaian setiap mata kuliah yang diajarkan.

- Meningkatkan kinerja dari pegawai dan elemen lainnya sehingga bisa lebih efektif dan efisien.

\section{» Persiapan Modul Perancangan E-Registration :}

- Modul Data Master : (1) Data master mahasiswa, (2) Data master dosen, (3) . Data master mata kuliah, kode dan kurikulum, (4) data master kalendar akademik, (5) Data master acara akademik harian, bulanan dan semester.

- Modul Pendaftaran/Registrasi mahasiswa: (1) Pendaftaran/regristrasi mahasiswa baru dan lama, (2) Pendaftaran ulang termasuk pemilihan mata kuliah dalam KRS, (3) Konsultasi Kepada Dosen Wali, (4) administrasi keuangan, (5) Pengisian kartu study komulatif.

- Modul database Pencarian Data : (1) Database Pencarian Data Dosen, Modul, (2) Database Pencarian Data Mahasiswa, (3) Database Pencarian Data Nilai Mata kuliah, (4) Database Pencarian Data Kegiatan Perkuliahan, (5) Database Administrasi Keuangan. 
- Modul Pencetakan Data : (1) Pencetakan Daftar Mata Kuliah, (2) Pencetakan Daftar Nilai KHS, (3) Pencetakan daftar nilai komulatif, (4) Pencetakan Pembayaran.

- Modul Statistik : Statistik Perkembangan Akademis akhir semester dan alumni.

\section{PERENCANAAN E- LEARNING.}

Pada era teknologi informasi sekarang ini, sebuah perguruan tinggi telah mulai menerapkan konsep E-Distance Learning sebagai metode pembelajaran bagi para mahasiswanya. Dengan E- Learning on-line hingga off-line, maka forum diskusi dengan materi-materi kuliah dapat didiskuasikan melalui email, blog, fasebook serta teleconfren sebagai sarana pencari dan memberi informasi perkuliahan. Bahkan link-link tertentu menuju suatu referensi, akan menjadi menu utama dalam web E- Learning resmi yang mereka publikasikan melalui internet. Dengan fasilitas inilah para mahasiswa, mereka dapat belajar kapan saja, dimana saja dan dari mana saja mereka mau sehingga waktu yang mereka miliki dapat lebih dimanfaatkan semaksimal mungkin.

o Kebutuhan Individu Mahasiswa :

- Akses, mencakup aspek : Peralatan, prosedur, dan fleksibilitas waktu dan kesempatan.

- Pendekatan yang komprehensif, mencakup : andal, akurat, lengkap, tepat cepat, terstruktur \& terorganisir serta terkomunikasikan.

- Keseimbangan antara training dan learning : Belajar secara mandiri maupun kelompok.

o Kebutuhan Pencitraan Perguruan Tinggi :

- Kontribusi kepada nilai-tambah sebuah perguruan tinggi membentuk citra : "the right information to the right people at the right time".

- Budaya keterbukaan : "Collective Intelligence"

- Optimalisasi : infrastruktur, sarana prasarana dan jangkauan.

- Pembelajaran : Akses, Fokus Tanformasi, Media, Fasilitas, Jadwal dan Admin.

Ada beberapa alasan penggunaan E-Learning di berbagai perguruan tinggi :

1. Digunakan sebagai media interaktif, menarik, dan menantang di dalam usaha meningkatkan pemahaman, pengertian dan pembelajaran dan pendidikan antara dosen dengan mahasiswa dalam proses belajar mengajar.

2. Pembelajaran yang terus menerus karena tidak diperlukannya sebuah tatap muka dan mahasiswa juga bisa selalu mempelajari sesuatu yang baru.

3. Dituntutnya peran aktif semua elemen untuk ikut selalu mengembangkan keilmuan. Untuk dosen pengajar dituntut untuk selalu memperbarui dan mencari sumber materi pustaka yang lebih bermutu dikarenakan mahasiswa bisa belajar dengan banyak di media web. Di satu sisi lain, mahasiswa dituntut juga untuk selalu bersaing dengan adanya informasi yang lengkap.

4. Mahasiswa bisa dimana dan kapan saja untuk belajar suatu mata perkuliahan atau yang lainnya. Dan dosen bisa saja memasukkan matede perkuliahan tertentu dan bisa 
memonitoring kegiatan belajar mahasiswanya.

5. Dapat diimplementasikan di lingkungan perguruan tinggi itu sendiri sehingga menghemat biaya operasional.

Maksud dan tujuan dari pengembangan E-Learning antara lain :

1. Menyediakan fasilitas penunjang kegiatan akademis terutama kegiatan pengembangan mutu belajar-mengajar.

2. Meningkatkan kinerja dari SDM Pengajar dan kompetisi belajar antar mahasiswa dari sebuah perguruan tinggi.

3. Menampilkan semua data mata kuliah dan pelatihan beserta matode yang mendukung.

4. Memonitoring perkembangan aktivitas proses belajar-mengajar.

5. Memudahkannya proses belajar dari mahasiswa dengan adanya fasilitas jaringan komputer kampus.

6. Mempunyai kemampuan menyajikan hasil dari perkuliahan yang telah ditempuh.

Keunggulan dan keuntungan yang diperoleh dari E-Learning Distance yaitu :

1. Dapat melaksanakan proses kegiatan pengelolaan manajemen kegiatan belajar mengajar secara terstruktur dan terintegrasi.

2. Mempermudah inventarisasi data mata kuliah dan kemahasiswaan secara cepat dan akurat.

3. Transfer Data dapat dilakukan secara on-line dan off-line.

4. Optimalisasi mutu pembelajaran.

5. Efisiensi waktu, tenaga dan biaya.

6. Dapat dilakukan pengawasan secara berkala.

7. Sistem aplikasi yang terintegrasi.

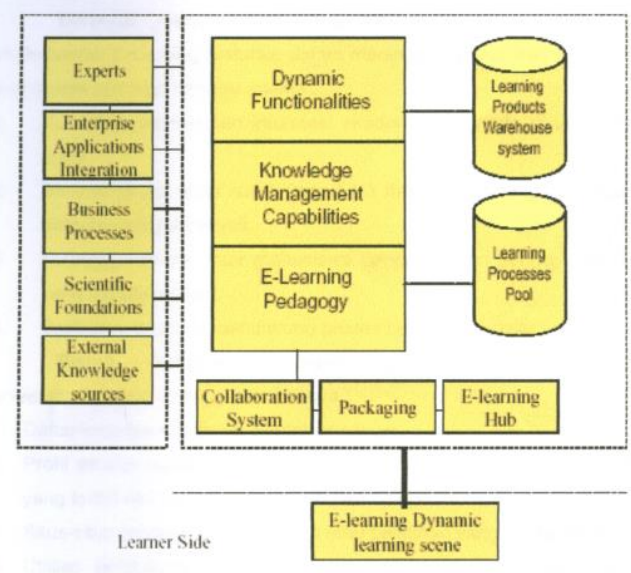

\section{CONTOH RANCANGAN MENU YANG DISAJIKAN :}

$\checkmark$ Menu utama : . Search, Events, News, Mail, Guest Book, Chat, Forum Discussion, Join Us, Administration, Links, User, Manual. 

(for events that allowed to register).

$\checkmark \quad$ News (Berita) : News, Past News, Add News.

$\checkmark \quad$ Mail :Check Mail, Send Mail.

$\checkmark$ Guest Book : View Guest Book, Add Guest Book.

$\checkmark \quad$ Chat : Register to Chat, hatting Media.

$\checkmark$ Discussion Forum : Discussion Forum Form, Details Discussion, Add New Thread (Topik), View Thread Message, Reply, : $\quad$ Edit Message (For auithor Log in only).

$\checkmark$ Registrasi / Join Us : Registration Form.

$\checkmark \quad$ Links : Add New Link : List of Link to Other Site.

$\checkmark$ Administration : Data Events, Edit Events, Add Event, $\quad$ News, Data News, Edit News, Add News, Data Guest Book, Add Comment, Discussion Forum, Edit Forum, New Forum, Links Form, Edit Links, Add Links Member (N/A), Member For, Edit member, Data Mata kuliah, Edit Mata Kuliah, Tambah Data Matkuliah, Data Dosen, Edit Data Dosen, Tambah Data Dosen, Trainer, Data Trainer, Edit Data Trainer, Tambah Data Trainer, Data Pengajaran Mata Kuliah, Edit Pengajaran Mata Kuliah, Pelatihan / Kursus, Data Pelatihan, Edit Data Pelatihan, Tambah Data Mahasiswa, Data Mahasiswa, Edit Data Mahasiswa, Tambah Data Mahasiswa, Data FRS, Edit Data FRS, Tambah Data FRS.

$\checkmark$ Materi Perkuliahan : Login, Data Materi Mata kuliah, Latihan Soal atau studi kasus, Materi Ujian/Tugas Akhir Mata Kuliah (pada waktu yang telah ditentukan) ,, Pengiriman jawaban ujian/ tugas, Nllai Akhir Mata Kuliah.

$\checkmark$ Materi Pelatihan/Kursus: Registrasi, Login, Data Materi Pelatihan atau Kursus,.Latihan Soal atau studi kasus Pelatihan atau Kursus, Materi Ujian/Tugas Akhir Mata Kuliah (pada waktu yang telah ditentukan), Nilai Akhir Pelatihan, .Pengiriman jawaban ujian/ tugas.

$\checkmark$ Statistik,
a. Statistik Pengunjung
b. Statistik Pembelajaran Materi
c. Statistik Pendaftaran
d. Statistik Ujian

\section{DAFTAR PUSTAKA}

McLeod, Raymond Jr. Management Information System. Edisi 9. Upper saddle River, Pearson Prentice Hall.

Kalakota, Ravi and Marcia Robinson (1999), E-Business : Roadmap for Success, Addison Wesley Longman. Inc.

Kenneth E. Kendall and Julie E. Kendall (2002), System Analysis and Design, Fifth Edition, Prentice 
Hall.

J. Supranto, M.A (2001), Pengukuran Tingkat Kepuasan Pelanggan, Rineka Cipta.

Budi Sutedjo(2001), Perspektif e-Business, Tinjauan Teknis Manajerial dan Strategi Andi Offset.

O'Brien, A, James (2004), Management Information System : Managing Information Technology in The Internetworked Enterprise (Sixth Edition), Irwin McGraw Hill.

Nicholas Negroponte, 2000, Being Digital random House.

Steve Lawrence, 2001, Online or Invisible Nature, http:// citeseer. 